\title{
Sinusoidal CD30-Positive Large B-Cell Lymphoma: A Morphologic Mimic of Anaplastic Large Cell Lymphoma
}

Raymond Lai, M.D., Ph.D., L. Jeffrey Medeiros, M.D., Laith Dabbagh, M.Sc., Kimberly S. Formenti, Robert W. Coupland, M.D.

Departments of Laboratory Medicine and Pathology, University of Alberta (RL), and Cross Cancer Institute (LD, KSF, RWC), Edmonton, Alberta, Canada; Department of Pathology, University of Texas MD Anderson Cancer Center, Houston, Texas (LJM)

Anaplastic large cell lymphoma (ALCL) has been recognized recently as a distinct clinicopathologic entity, restricted to a subset of CD30-positive diffuse large cell lymphomas of T/null lineage. Some of the characteristic features of ALCL, such as CD30 antigen expression and the presence of large pleomorphic lymphoid cells infiltrating lymph node sinuses, can be found rarely in diffuse large B-cell lymphomas. We collected 11 such cases, and their clinical, morphologic, and immunophenotypic features are reviewed. The age of the patients ranged from 36 to 82 years (mean, 63.2 years) with a male to female ratio of 1:1.2. All neoplasms were nodal with a sinusoidal infiltrative pattern, although four neoplasms also had foci of confluent growth. Eight tumors were composed predominantly of large pleomorphic cells with occasional Reed-Sternberg-like cells. The other three tumors had a higher proportion of large monomorphic lymphoid cells. Necrosis and admixed granulocytes were other common features. Immunophenotypically, all cases were positive for CD30 and CD20 or CD79a. All eight cases examined for anaplastic lymphoma kinase-1 immunoreactivity were negative. In situ hybridization for EpsteinBarr virus RNA was performed in eight cases; two were positive. Excluding one consultation case with no available clinical follow-up data, six patients died of the disease within 3 years and one had disease relapse within 1 year. We conclude that an unusual variant of diffuse large B-cell lymphoma can closely mimic ALCL. However, these neoplasms can be distinguished from ALCL by virtue of their B-lineage and lack of anaplastic lymphoma kinase-1 expression. Evidence of Epstein-Barr virus

Copyright () 2000 by The United States and Canadian Academy of Pathology, Inc.

VOL. 13, NO. 3, P. 223, 2000 Printed in the U.S.A.

Date of acceptance: August 24, 1999.

Address reprint requests to: Raymond Lai, M.D., Ph.D., 4B2.21 University of Alberta Hospital, 8440-112 Street, Edmonton, Alberta, Canada T6G $2 \mathrm{~B} 7$. infection can be found in a small subset of these neoplasms.

KEY WORDS: CD30, Large B-cell lymphoma, Sinusoidal.

Mod Pathol 2000;13(3):223-228

Anaplastic large cell lymphoma (ALCL), first described as Ki-1 (CD30)-positive large cell lymphoma, has been recognized as a clinicopathologic entity (1). ALCL was originally described by Stein $e t$ al. (2) as a neoplasm composed of large pleomorphic lymphoid cells that express the CD30 antigen and have a propensity to involve lymph node sinuses. Although most of these lymphomas were of $\mathrm{T} /$ null lineage, some cases were of B-cell lineage. More recent, it has been recognized that ALCL can exhibit a broad spectrum of cytologic features (3). Furthermore, a subset of ALCL overexpresses anaplastic lymphoma kinase (ALK)-1 as a result of a characteristic cytogenetic abnormality, $\mathrm{t}(2 ; 5)(\mathrm{p} 23$; q35), and is associated with young patient age and better prognosis $(4,5)$. In contrast to ALCL of T/null lineage, most CD30-positive large B-cell lymphomas do not carry the $t(2 ; 5)(p 23 ; q 35)$, are negative for ALK-1, and clinically behave worse than ALCL and more similar to diffuse large B-cell lymphomas $(6,7)$. Thus, CD30-positive large B-cell lymphoma has been excluded from the ALCL category in the revised European-American classification of lymphoid neoplasm and the recently proposed World Health Organization classification systems $(6,8)$.

Diffuse large B-cell lymphoma can selectively and predominantly infiltrate lymph node sinuses; this pattern has been recognized as an unusual morphologic variant of this entity (9). Probably related to its rarity, it has not been well characterized. A subset of sinusoidal large B-cell lymphomas are the so-called "microvillous lymphomas," but these neoplasms are uniformly negative for CD30 $(10,11)$. Sinusoidal large B-cell lymphomas with CD30 expression are even more rare. To our knowledge, 
only three such cases were briefly described in one recent report; all three patients had a history of follicular lymphoma before transformation to CD30-positive large B-cell lymphoma (12). We collected 11 cases of CD30-positive, sinusoidal large B-cell lymphomas in patients without a previous history of lymphoma, and the clinical, morphologic, and immunophenotypic features of these cases are presented.

\section{MATERIALS AND METHODS}

\section{Case Selection}

All 11 cases were found and collected from the files of the Department of Laboratory Medicine and Pathology at the Cross Cancer Institute. We initially searched our files from 1989 to 1999 for a diagnosis of diffuse large B-cell lymphoma with immunohistochemical results of CD30 expression. All cases of diffuse large B-cell lymphoma with CD30 positivity were reviewed, and cases were selected on the basis of the following criteria: 1) diffuse large cell lymphoma; 2) B-cell lineage, as established by CD20 and/or CD79a expression by immunohistochemistry; 3 ) evidence of a sinusoidal growth pattern; and 4) by immunohistochemistry, more than $50 \%$ of tumor cells showing expression of the CD30 antigen in the evenly stained areas. Hematoxylin-eosin stains were performed on formalin-fixed, paraffinembedded tissue sections.

\section{Immunohistochemistry}

Monoclonal antibodies specific for the following antigens were used: CD3, 1:50 (Novocastra Laboratories, Newcastle upon Tyne, UK); CD15 (LeuM1), 1:5 (Becton Dickinson, San Jose, CA); CD20 (L26), 1:100; CD30 (BerH2), 1:5; CD45 (2D1), 1:20; CD79a, 1:5; EMA (E29), 1:20; and ALK-1, 1:25 (DAKO, Mississauga, Ontario, Canada).

Tissue sections were mounted onto precleaned slides (Superfrost; Fisher Scientific, Pittsburgh, PA), baked at $56^{\circ} \mathrm{C}$ for $60 \mathrm{~min}$, deparaffinized with xy- lene, and rehydrated with ethanol to distilled water. A prestaining heat-induced antigen retrieval method was used, as previously described (13). Briefly, tissue sections were placed in sodium citrate buffer $(0.01 \mathrm{~mol} / \mathrm{L}, \mathrm{pH}$ 6.0) and heated in a microwave oven for $10 \mathrm{~min}$. An automated immunostainer (Ventana Biotek Medical Systems, Tucson, AZ) was used. Reactivity was detected by an avidin-biotin immunoperoxidase method with 3,3' diaminobenzidine-tetrahydrochloride dihydrate (Ventana Biotek Medical System) as the chromogen.

\section{In Situ Epstein-Barr Virus Hybridization}

In situ hybridization studies to detect EpsteinBarr virus (EBV) RNA were performed using a 30base oligonucleotide complementary to a portion of EBER1 genome that is actively transcribed (up to $10^{7}$ copies per cell) in latently infected cells. The methods have been detailed elsewhere (14).

\section{RESULTS}

\section{Clinical Data}

A total of 11 cases were identified. The clinical data of these 11 patients are summarized in Table 1. With the exception of one consultation case $(\mathrm{Pa}-$ tient 4), all patients were treated and followed up at the Cross Cancer Institute. There were five men and 6 women, who ranged in age from 36 to 82 years (mean, 63.2 years). Excluding Patient 4, for whom detailed clinical data were not available, all patients presented with primary nodal disease, and all of them were treated with a curative intent, receiving standard combination chemotherapy including CHOP (cyclophosphamide, hydroxydaunomycin, Oncovin, and prednisone) with or without localized radiotherapy. One patient (Patient 8) also had an autologous bone marrow transplantation after relapse. Overall, 6 of 10 patients died of disease (mean survival, 12.7 months). Of the remaining four patients, one (Patient 8) had relapse within 1 year,

TABLE 1. Clinical Data

\begin{tabular}{|c|c|c|c|c|}
\hline Patient & Age/Sex & Presentation Sites & $\begin{array}{c}\text { Ann Arbor } \\
\text { Stage }\end{array}$ & Clinical Outcome \\
\hline 1 & $58 \mathrm{~F}$ & Cervical lymph nodes & II & Alive without disease 11 months after diagnosis \\
\hline 2 & $67 \mathrm{~F}$ & Axillary lymph nodes & I & Deceased 9 months after diagnosis \\
\hline 3 & $69 \mathrm{~F}$ & Inguinal/Abdominal lymph nodes & IV & Alive without disease 14 months after diagnosis \\
\hline 4 & $62 \mathrm{M}$ & Supraclavicular lymph nodes & NA & NA \\
\hline 5 & $66 \mathrm{~F}$ & Neck lymph nodes & IV & Deceased 15 months after diagnosis \\
\hline 6 & $64 \mathrm{~F}$ & Peri-aortic lymph nodes & II & Deceased 2 months after diagnosis \\
\hline 7 & $36 \mathrm{M}$ & Cervical/abdominal lymph nodes & IVB & Alive without disease 24 months after diagnosis \\
\hline 8 & $40 \mathrm{M}$ & Cervical lymph nodes & IIIA & Relapsed 6 months after diagnosis; alive without disease after BMT \\
\hline 9 & $79 \mathrm{M}$ & Groin lymph nodes & IA & Deceased 9 months after diagnosis \\
\hline 10 & $82 \mathrm{M}$ & Intra-abdominal lymph nodes & IVB & Deceased 14 months after diagnosis \\
\hline 11 & $72 \mathrm{~F}$ & Axillary lymph nodes & IVB & Deceased 27 months after diagnosis \\
\hline
\end{tabular}

NA, not available; BMT, bone marrow transplantation. 
which necessitated bone marrow transplantation. Three were alive without evidence of disease, although two of these three patients were recently diagnosed, with the follow-up time period being 11 months and 14 months, respectively. Other than Patient 4, whose HIV status was unknown, all of the other patients had no known risk factors for HIV infection. In addition, none of these patients had a previous history of lymphoma.

\section{Histologic Findings}

All 11 cases were originally diagnosed as diffuse large cell lymphoma involving lymph nodes. All cases had evidence of a sinusoidal growth pattern, often associated with residual atrophic lymphoid follicles (Fig. 1). A subset (4 of 11) contained foci of confluent tumor cell growth. Focally, the tumor cells showed apparent cohesiveness. All cases contained large pleomorphic lymphoid cells with polylobulated nuclei, vesicular chromatin, prominent nucleoli, and abundant amphophilic cytoplasm (Fig. 2), although some cases (3 of 11) also contained a population of monomorphic large lymphoid cells (Fig. 3). Scattered Reed-Sternberg-like cells were also seen in some cases. Necrosis and admixed neutrophils were the other more common findings. Notably, tumor cells with an eosinophilic paranuclear region were absent.

\section{Immunohistochemical Findings}

The results of the immunohistochemical studies are summarized in Table 2. All cases were positive

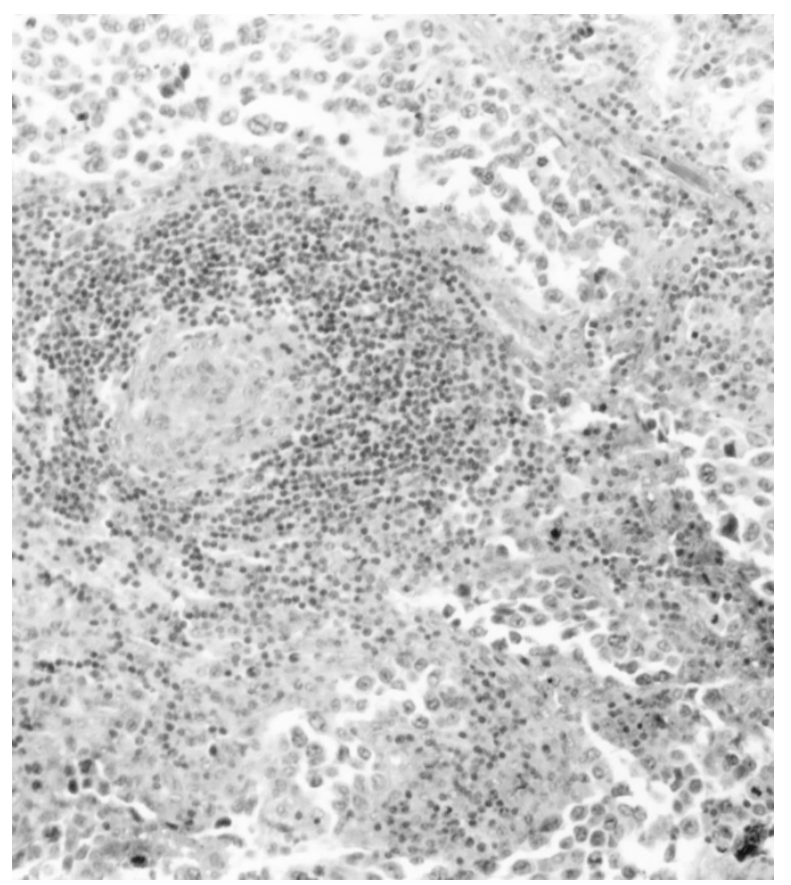

FIGURE 1. A low magnification of a case of CD30-positive sinusoidal large B-cell lymphoma. Note the expansion of the sinuses by neoplastic cells and the surrounding residual atrophic lymphoid follicles (hematoxylin and eosin, 100×).

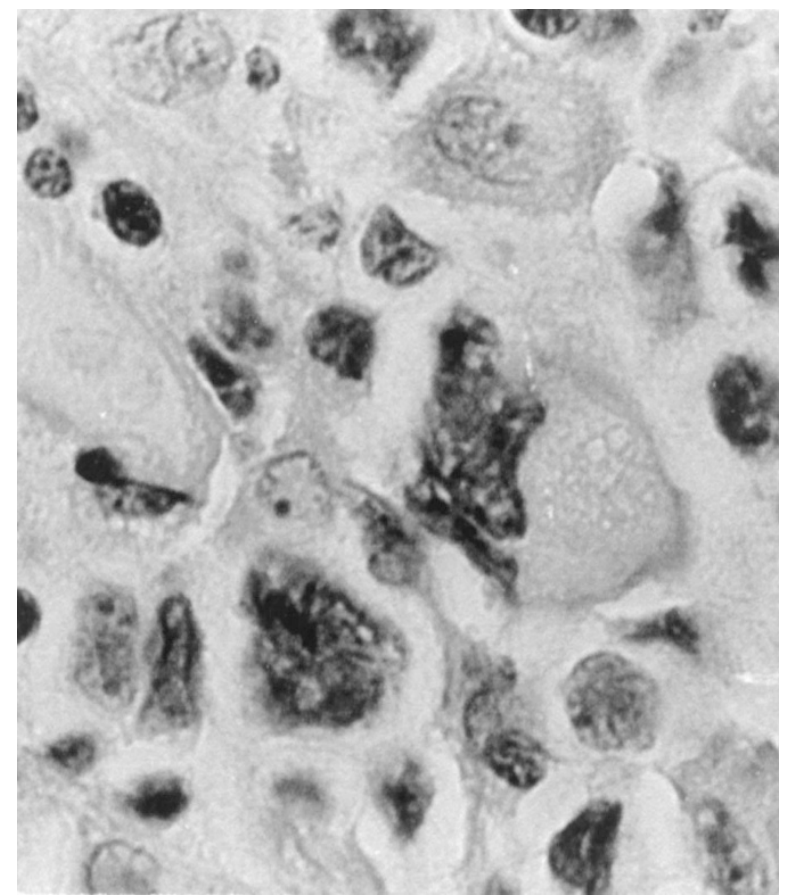

FIGURE 2. A high magnification of the same case as in Figure 1, illustrating the anaplastic cytology of the tumor cells (hematoxylin and eosin, $400 \times)$.

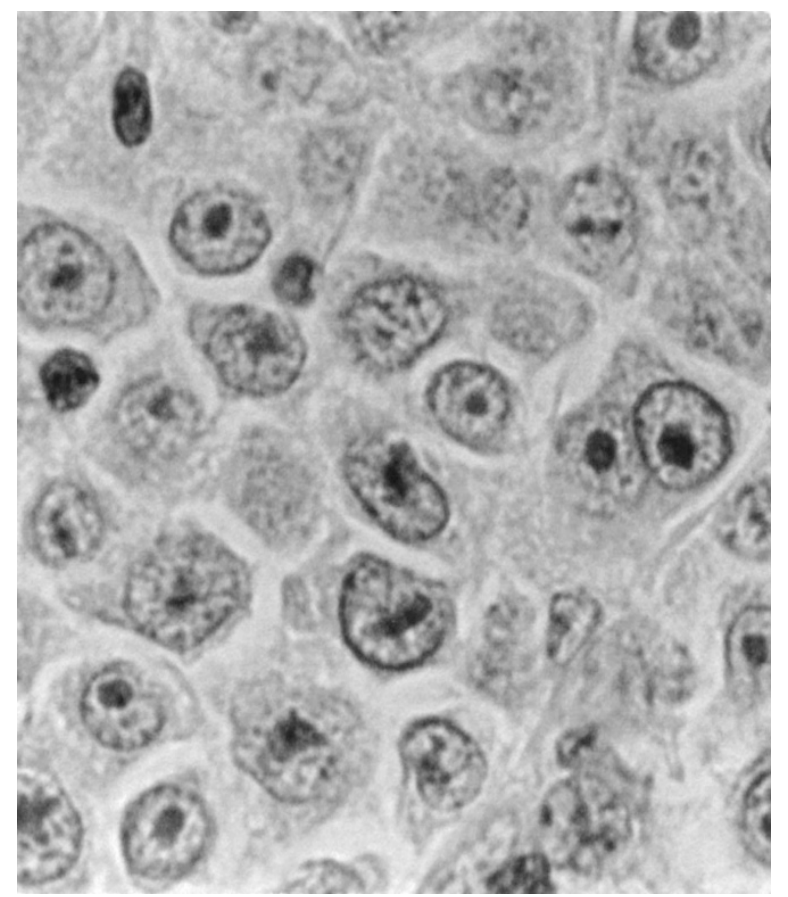

FIGURE 3. A high magnification of a case of CD30-positive sinusoidal large B-cell lymphoma, which also contained a population of monomorphic immunoblasts (hematoxylin and eosin, 400×).

for CD20 and/or CD79a (Fig. 4a) and negative for $\mathrm{CD} 3$, confirming their B-cell lineage. Each neoplasm was also positive for CD45 and CD30 (Fig. $4 \mathrm{~b})$. None of eight cases tested was positive for ALK-1. One of six cases assessed was positive for EMA. 
TABLE 2. Immunohistochemical and In Situ EBV Studies

\begin{tabular}{ccccccccc}
\hline Patient & CD3 & CD20 & CD79a & CD30 & ALK-1 & EMA & CD45 & EBV In Situ \\
\hline 1 & - & + & ND & + & - & ND & + & - \\
2 & - & - & + & + & - & ND & + & - \\
3 & - & + & ND & + & - & - & ND & - \\
4 & - & + & ND & + & ND & ND & ND & + \\
5 & - & + & ND & + & - & - & + & - \\
6 & - & - & + & + & ND & + & + & - \\
7 & - & + & ND & + & - & - & + & - \\
8 & - & + & ND & + & - & - & ND & ND \\
9 & - & + & + & + & - & - & + & ND \\
10 & - & + & ND & + & - & ND & + & + \\
11 & - & + & ND & + & ND & ND & ND & ND \\
Total & $0 / 11$ & $9 / 11$ & $3 / 3$ & $11 / 11$ & $0 / 8$ & $1 / 6$ & $7 / 7$ & $2 / 8$ \\
\hline
\end{tabular}

ALK, anaplastic lymphoma kinase; EBV, Epstein-Barr virus; ND, not determined.

\section{In Situ EBV Studies}

Two of these 11 cases (Patients 4 and 10) were positive for EBV by in situ hybridization. The HIV status of Patient 4 (consultation case) was unknown, and a positive signal was detected in 30 to $40 \%$ of the tumor cells (Fig. 5). The other positive case (Patient 10) was from an 82-year-old man with no known risk factors for HIV infection; a positive signal was detected in roughly $10 \%$ of the tumor cells.

\section{DISCUSSION}

We describe 11 cases of a highly unusual variant of nodal diffuse large B-cell lymphoma, characterized by the coexistence of a sinusoidal infiltrative pattern and CD30 expression. Although sinusoidal large B-cell lymphomas have been described (9) and CD30 expression in a subset of diffuse large B-cell lymphoma is widely recognized, only three cases of CD30-positive large B-cell lymphoma that also had a sinusoidal pattern have been described; all had a history of follicular lymphoma (12). In contrast to these three previously reported cases, all of the cases described here were from patients without a previous history of lymphoma.

Most cases ( 8 of 11) were composed predominantly of cells with cytologic features similar to those seen in the classic type of anaplastic large cell lymphoma. The cytologic features, cohesiveness of the tumor cells, and the sinusoidal growth pattern are suggestive of metastatic carcinoma and melanoma, which can be excluded by the appropriate immunohistochemical studies. The overall morphologic features and the CD30 positivity also make these lesions a close mimic of ALCL. However, despite the overall histologic similarities with ALCL, neoplastic cells with an eosinophilic paranuclear region, which have been reported as a constant finding for ALK-positive ALCL (3), were absent. These tumors can be further distinguished from ALCL by virtue of their B-cell lineage, uniform CD45 expression, infrequent EMA positivity, and the absence of ALK-1 expression.

In addition to ALCL and metastatic melanoma/ carcinoma, the other entities that should be included in the differential diagnosis are microvillous lymphoma and the recently described diffuse large cell lymphomas that express ALK but without $t(2 ; 5)$ or CD30 expression. Despite the close morphologic similarities, microvillous lymphomas are uniformly
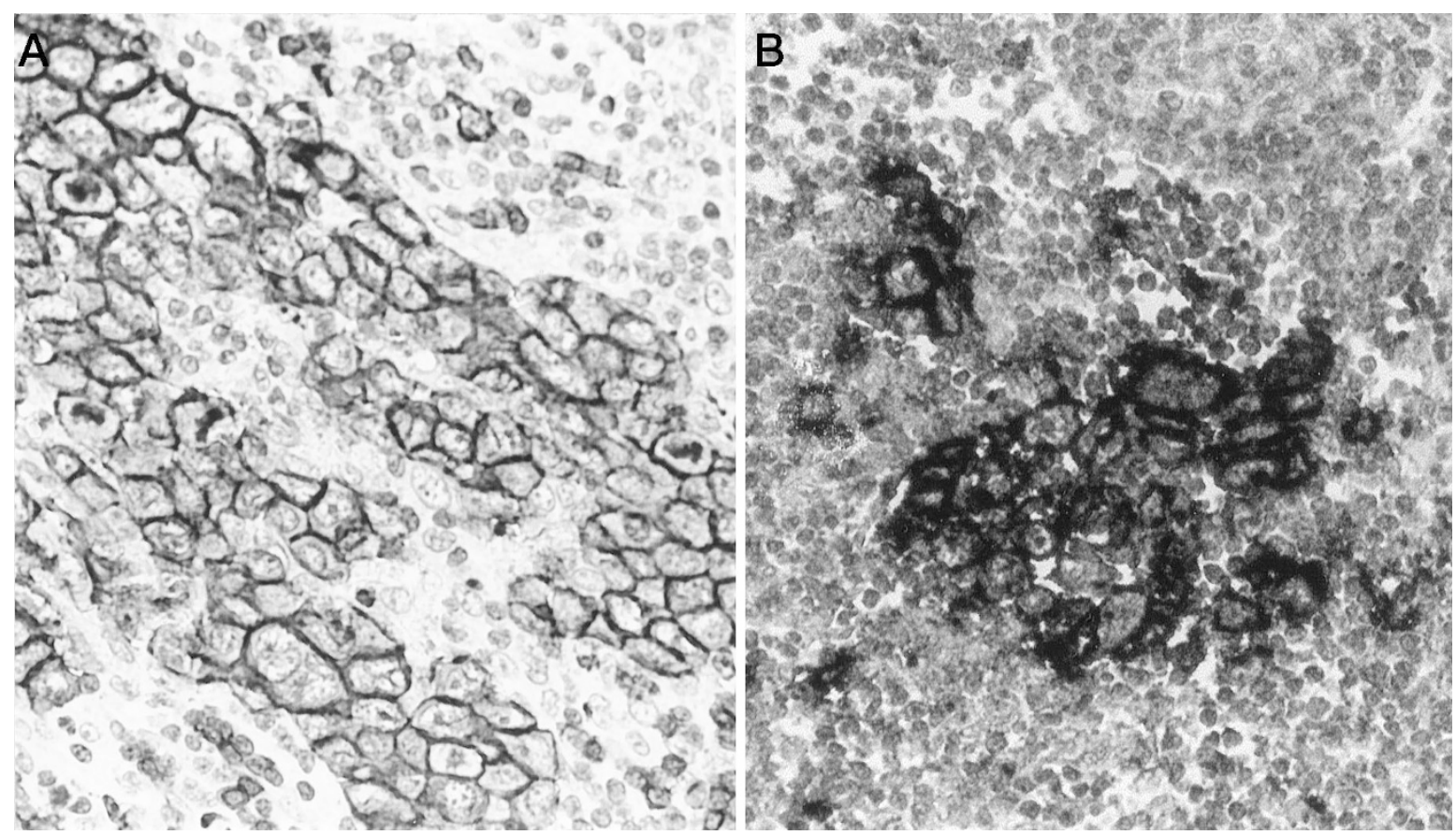

FIGURE 4. The tumor cells were strongly positive for CD20 (A) and CD30 (B) (immunoperoxidase, 400×). 


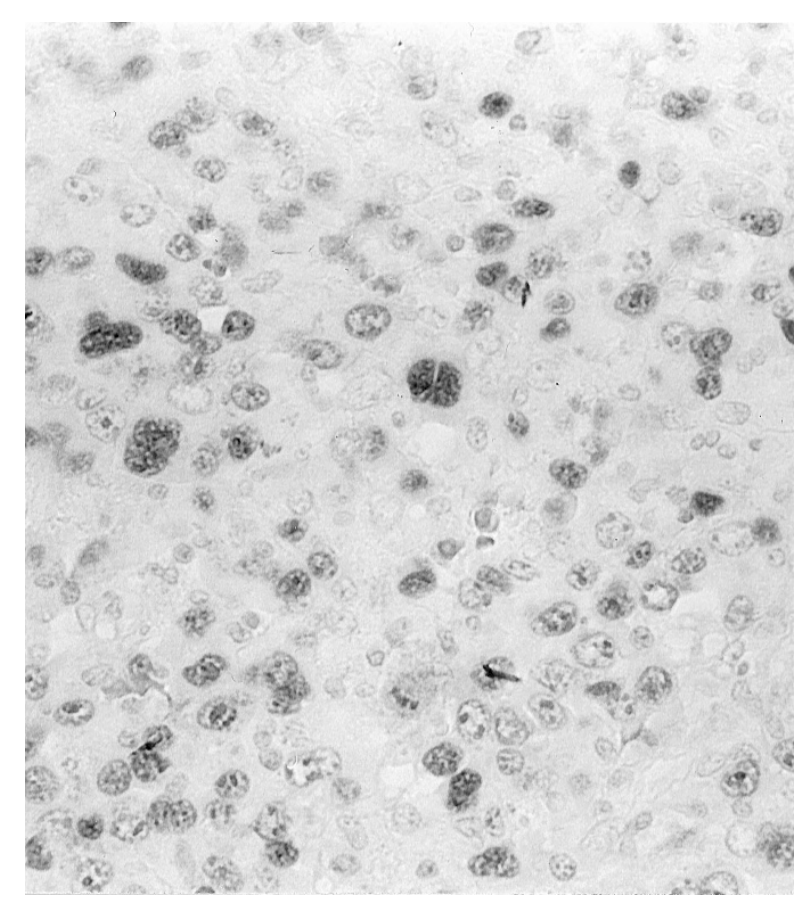

FIGURE 5. In situ hybridization for Epstein-Barr virus RNA showing the presence of many positive tumor cells in Patient 4 (original magnification, $400 \times)$.

CD30 negative (10). Similar to our cases, the subtype of diffuse large B-cell lymphomas described by Delsol et al. (15) generally have a sinusoidal pattern. However, they are composed of monomorphic immunoblasts, and they differ immunophenotypically from our cases, being uniformly CD30 negative, EMA positive, and ALK positive.

Clinically, sinusoidal CD30-positive large B-cell lymphomas seem to be largely a disease of older individuals. In our series, the mean age was 63.2 years and 9 of 11 patients were older than 55 years. The male-to-female ratio was 1:1.2. These data are similar to those of standard diffuse large cell lymphomas (mean age, 57 years; male-to-female ratio, 1:1) (9). Despite treatment, most (6 of 10) died of the disease with a relatively short mean survival (12.7 months). In addition, one of the remaining four patients relapsed 6 months after the diagnosis. Thus, these tumors are associated with a worse clinical outcome than that with diffuse large B-cell lymphoma as a group, which has been reported to have a remission rate of $80 \%$ and an overall survival rate of $60 \%$ (16). It is interesting that the three cases of CD30-positive sinusoidal large B-cell lymphoma described by Alsabeh et al. (12) also did poorly: one patient died 10 months after diagnosis, and two patients had relapse of the disease shortly after bone marrow transplantation. Although it has been shown that CD30 expression in diffuse large B-cell lymphoma does not have any significant impact on survival (7), large B-cell lymphoma with CD30 positivity and a sinusoidal growth pattern may in fact carry a poor prognosis.
We found evidence of EBV infection in 2 of these 11 cases by in situ hybridization. EBV also has been demonstrated in some cases of ALCL (17). It is possible that EBV may play a role in contributing to the pathogenesis of some of these neoplasms. EBV also may be related to the CD30 expression observed in these tumors, because some EBV-related immunoblastic proliferations are known to express CD30 (18).

\section{CONCLUSION}

We presented 11 cases of CD30-positive sinusoidal large B-cell lymphoma, which can closely mimic ALCL. Despite the morphologic and immunophenotypic similarities, they can be distinguished from ALCL by virtue of their B-cell lineage, lack of ALK-1 expression, and lack of cells with an eosinophilic paranuclear region. As a group, they seem to behave aggressively and may be worse than standard diffuse large B-cell lymphomas. Although the biologic nature of these neoplasms is yet to be defined, EBV may play a role in the pathogenesis of some of these neoplasms.

\section{REFERENCES}

1. Kadin ME. Primary Ki-1-positive anaplastic large-cell lymphoma: a distinct clinicopathologic entity. Ann Oncol 1994; $5: S 25-30$.

2. Stein H, Mason DY, Gerdes J, O'Connor N, Wainscoat J, Pallesen G, et al. The expression of Hodgkin's disease associated antigen Ki-1 in reactive and neoplastic lymphoid tissue: evidence of Reed-Sternberg cells and histiocytic malignancies are derived from activated lymphoid cells. Blood 1985;66:848-58.

3. Benharroch D, Meguerian-Bedoyan Z, Lamant L, Amin C, Brugieres L, Terrier-Lacombe M, et al. ALK-positive lymphoma: a single disease with a broad spectrum of morphology. Blood 1998;91:2076-84.

4. Nakamura S, Shiota M, Nakagawa A, Yatabe Y, Kojima M, Motoort T, et al. Anaplastic large cell lymphoma: A distinct molecular pathologic entity: a reappraisal with special reference to p80 NPM/ALK expression. Am J Surg Pathol 1997; 21:1420-32.

5. Pulford K, Lamant L, Morris SW, Butler LH, Wood KM, Stroud D, et al. Detection of anaplastic lymphoma kinase (ALK) and nucleolar protein nucleoplasmin (NPM)-ALK proteins in normal and neoplastic cells with the monoclonal antibody ALK1. Blood 1997;89:1394-404.

6. Harris NL, Jaffe ES, Stein H, Banks PM, Chan JK, Cleary ML, et al. A revised European-American classification of lymphoid neoplasms: a proposal from the International Lymphoma Study Group. Blood 1994;84:1361-92.

7. Noorduyn LA, Bruin PC, van Heerde P, van de Sandt MM, Ossenkoppele GJ, Meijer CJLM. Relation of CD30 expression to survival and morphology in large cell B cell lymphoma. J Clin Pathol 1994;47:33-7.

8. Jaffe ES, Harris NL, Diebold J, Muller-Hermelink HK. World Health Organization Classification of lymphomas: a work in progress. Ann Oncol 1998;9(Suppl 5):S25-30.

9. Warnke RA, Weiss LM, Chan JKC, Cleary ML, Dorfman RF. Malignant lymphoma, diffuse, large cell and variants. In: 
Rosai J, editor. Atlas of tumor pathology: tumors of the lymph nodes and spleen. Washington, DC: Armed Forces Institute of Pathology; 1994. pp. 153-220.

10. Kinney MC, Glick AD, Stein H, Collins RD. Comparison of anaplastic large cell Ki-1 lymphomas and microvillous lymphomas in their immunologic and ultrastructural features. Am J Surg Pathol 1990;14:1047-60.

11. Hammer RD, Vnencak-Jones CL, Manning SS, Glick AD, Kinney MC. Microvillous lymphomas are B-cell neoplasms that frequently express CD56. Mod Pathol 1998;11:239-46.

12. Alsabeh R, Medeiros LJ, Glackin C, Weiss LM. Transformation of follicular lymphoma into CD30-large cell lymphoma with anaplastic cytologic features. Am J Surg Pathol 1997;21: 528-36.

13. Battifora H, Alsabeh R, Jenkins KA, Gown A. Epitope retrieval (unmasking) in immunohistochemistry. Adv Pathol Lab Med 1995;8:101-18.

14. Ambinder RF, Browning PJ, Lorenzana I, Leventhal BG, Co- senza H, Mann RB, et al. Epstein-Barr virus and childhood Hodgkin's disease in Honduras and the United States. Blood 1993;81:462-7.

15. Delsol G, Lamant L, Mariame B, Pulford K, Dastugue N, Brousset $\mathrm{P}$, et al. A new subtype of large B-cell lymphoma expressing the ALK kinase and lacking the 2;5 translocation. Blood 1997;89:1483-90.

16. Urba WJ, Duffey PL, Longo DL. Treatment of patients with aggressive lymphomas: an overview. J Natl Cancer Inst Monogr 1990;10:29-37.

17. Shimakage M, Nakamine H, Tamura S, Takenaka T, Yutsudo M, Hakura A. Detection of Epstein-Barr virus transcripts in anaplastic large-cell lymphomas by mRNA in situ hybridization. Hum Pathol 1997;28:1415-9.

18. Segal GH, Kjeldsberg CR, Smith GP, Perkins SL. CD30 antigen expression in florid immunoblastic proliferations: a clinicopathologic study of 14 cases. Am J Clin Pathol 1994;102: 292-8.

\section{Book Review}

\section{Fenoglio-Preiser CM, Noffsinger AE, Stemmer- mann GN, Lantz PE, Listrom MB, Rilke FO: Gastrointestinal Pathology: An Atlas and Text, 1312 pp, Philadelphia, Lippincott Wil- liams \& Wilkins, 1999 (\$299).}

This is the second edition of a textbook of gastrointestinal pathology, first published in 1989. It covers the neoplastic and non-neoplastic diseases of the esophagus, stomach, and intestines, illustrating the salient points with high-quality photographs. The text was updated and the inventory of pictures was expanded so that this second edition is almost 400 pages thicker than its predecessor.

Dr. Fenoglio-Preiser and her team (which has also undergone some changes from one edition to another) are well-read and experienced gastrointestinal pathologists as evidenced by their discussion of complex issues, encyclopedic coverage of the material, and an outstanding collection of illustrations. In addition to the usual stuff that can be found with some variation in other texts, this book excels in presenting hardto-find gross specimens and not-so-common variants of common diseases. Where else could one find a picture of a specimen of tracheo- esophageal fistula or prostaglandin gastropathy so meticulously dissected? For an example of how the authors treat common diseases, just look up the chapter on colonic polyps and cancers. Diagrams are used to explain concepts or current theories, such as the pathogenetic role of Helicobacter pylori, or to summarize the clinical features of the hereditary colon cancer syndromes. Tables are used to present salient pathologic features of important diseases for quick review or to provide lists of etiologic agents.

This is an elegant, esthetically pleasing atlas garnished with an erudite text. It gives an excellent overview of advances and discoveries that took place in the field of gastrointestinal pathology during the past 10 years, enough to keep you au courant for the next few years, until the third edition comes out. This book is a treasure trove of gross and microscopic images that deserves to be revisited from time to time by practicing pathologists, gastroenterologists, and surgeons who deal with the alimentary tract diseases.

\section{Ivan Damjanov \\ University of Kansas School of Medicine \\ Kansas City, Kansas}

